\title{
CONTROLADOR DIGITAL APLICADO A CONVERSOR DE TENSÃO AUTOMOTIVO
}

\author{
Ericsson Lara ${ }^{1.2}$, Roberto d'Amore ${ }^{1}$, Glenan Lago ${ }^{2}$ e Julio Lucchi ${ }^{3}$ \\ ${ }^{1}$ Instituto Tecnológico de Aeronáutica - ITA \\ ${ }^{2}$ Continental Brasil Indústria Automotiva Ltda. \\ ${ }^{3}$ Universidade São Judas Tadeu - USJT \\ E-mails: ericsson.lara@ continental-corporation.com, damore@ita.com.br, \\ glenan.lago@continental-corporation.com, prof.julio@usjt.br
}

\section{RESUMO}

Com a crescente complexidade dos sistemas embarcados, conversores de tensão, amplamente utilizados em veículos comerciais e essenciais para a tecnologia de veículos híbridos, necessitam de integração às redes de informações veiculares. Ao mesmo tempo, requisitos cada vez mais exigentes quanto a desperdício de energia regem o desenvolvimento de novos módulos eletrônicos. Este trabalho apresenta uma plataforma para estudos de conversores de energia chaveados automotivos, empregando controladores digitais programados em dispositivos do tipo DSP. A sua robustez com relação à variação de carga é testada. A eficiência energética da conversão pôde ser otimizada através do ajuste do tempo morto, resultando em um ganho de $0,36 \%$. O tempo de execução do controlador, para o caso de um algoritmo de controle PID, resultou em 15us, demonstrando a possibilidade de se realizar comunicação com redes embarcadas.

\section{INTRODUÇÃO}

Conversores de energia chaveados são circuitos que convertem a natureza da energia elétrica em sua entrada para o uso de outro sistema. Seu funcionamento é baseado no chaveamento e filtragem de porções exatas da energia de sua entrada para maximizar o rendimento energético. Sua estrutura básica é apresentada na Figura 1.

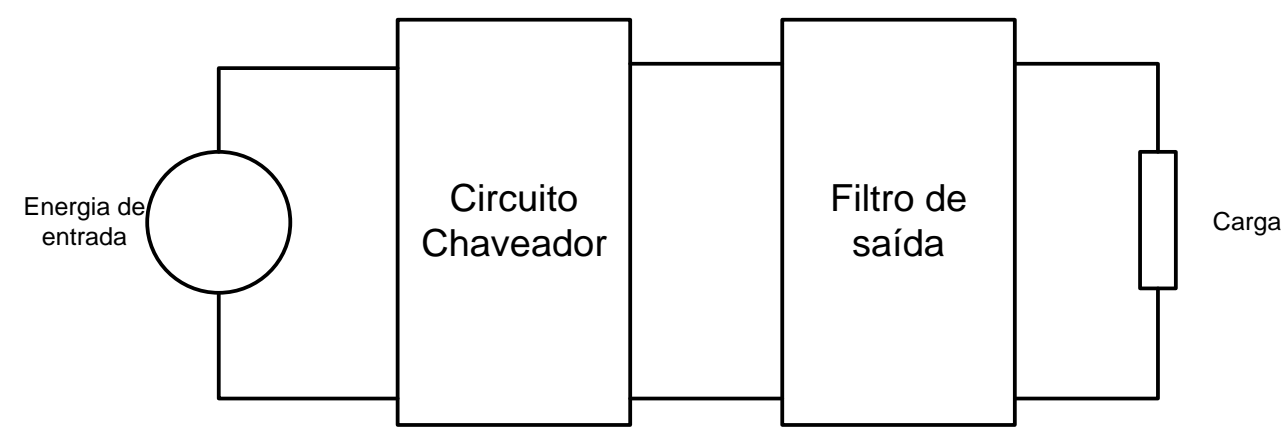

Figura 1 - Estrutura básica de conversor de energia 
Um conversor é denominado DC-DC quando apenas o nível de tensão ou corrente de sua saída é alterado: tanto a entrada quando a saída permanecem em nível contínuo [1]. Conversores DC-DC são utilizados em veículos comerciais, cuja bateria é normalmente de $24 \mathrm{~V}$, para alimentar módulos de veículos de passeio com tensão de $12 \mathrm{~V}$, como, por exemplo, um auto radio ou uma tomada de alimentação para o motorista. Em veículos híbridos, conversores DC-DC têm a função de fornecer tensão e corrente adequadas para carregar baterias quando em regeneração [2]. As aplicações de conversores de tensão DC-DC automotivos têm em comum a natureza aleatória da carga que alimentam. Deste modo, tais conversores necessitam de circuitos de controle para torná-los robustos a estas variações. Estes circuitos medem algumas grandezas elétricas na saída e ajustam atuadores (circuito chaveador) para compensar possíveis variações, conforme ilustrado na Figura 2.

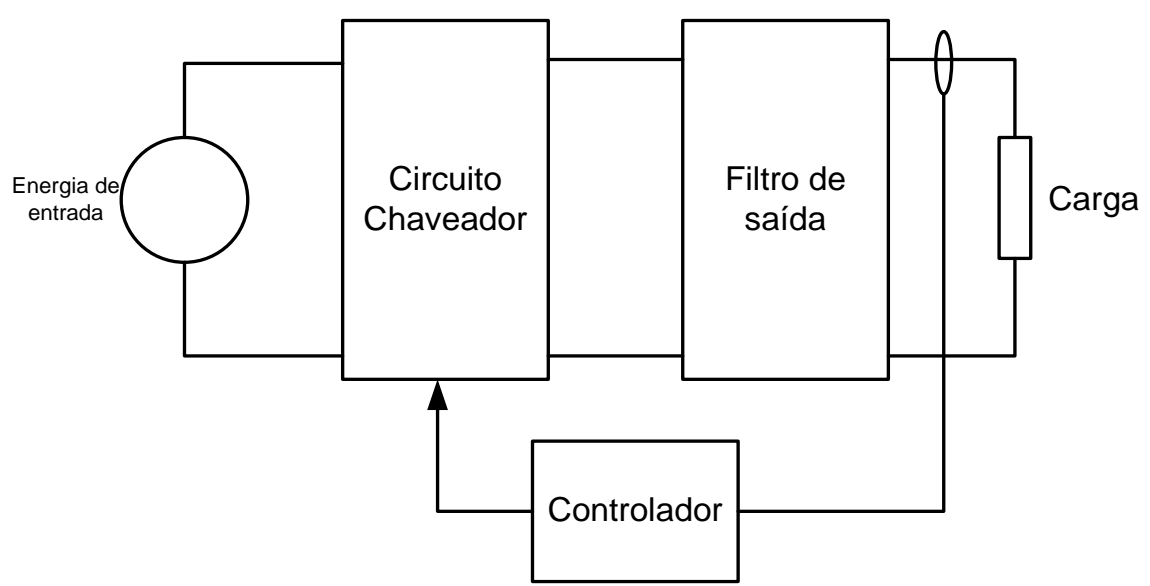

Figura 2 - Controlador aplicado a conversores de energia

Conversores de energia automotivos com integração com redes de dados embarcadas são necessários devido à demanda por informações de falhas ou estado do sistema. Porém, conforme [3], a maior parte dos conversores utiliza circuitos de controle analógico, sem capacidade de interagir diretamente com redes de dados. Muitas soluções adotam um circuito monitor digital quando é necessária esta interface, veja Figura 3. Além disso, controladores analógicos empregam estratégias de controle fixas que não podem ser alteradas [3]. 


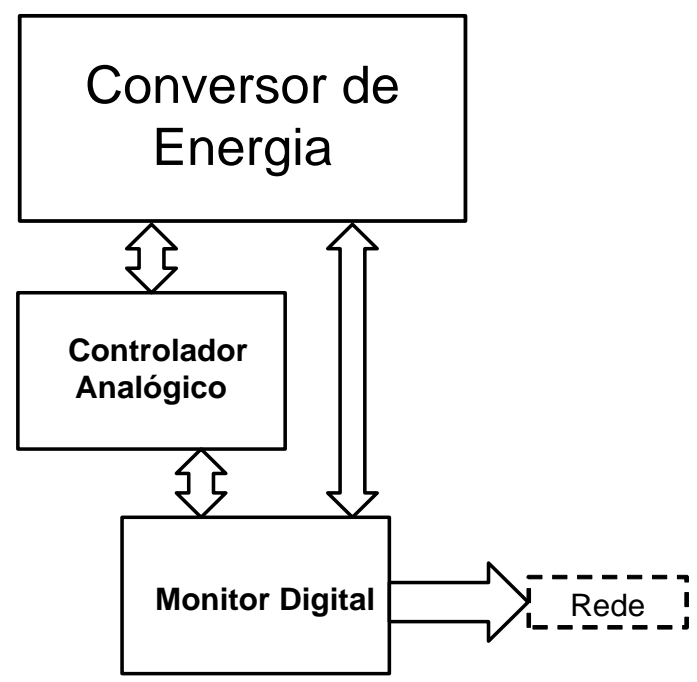

Figura 3 - Conversor de energia com monitor digital

A plataforma de estudos proposta tem como objetivo viabilizar a análise de estratégias de controle empregando um processador digital de sinais (DSP) para realizar tanto as operações de um controlador analógico quanto a comunicação com redes externas. O resultado final a ser atingido nos estudos empregando a plataforma é a seleção do sistema de menor custo que atenda aos requisitos especificados.

A plataforma de estudos proposta emprega a topologia Buck Síncrona; topologia básica de conversores DC-DC com redução de tensão [1] [4]. Como os resultados de análise obtidos com esta topologia podem ser estendidos para todas outras topologias de conversores DC-DC [5], o emprego de uma tecnologia fixa não limita a flexibilidade de aplicação da plataforma proposta.

\section{PLATAFORMA}

A plataforma desenvolvida possui capacidade de fornecer até $405 \mathrm{~W}$ à carga de saída a partir de uma fonte de entrada com até $30 \mathrm{~V}$. Ela possui três blocos básicos: Conversor, DSP e Interface, veja Figura 4.

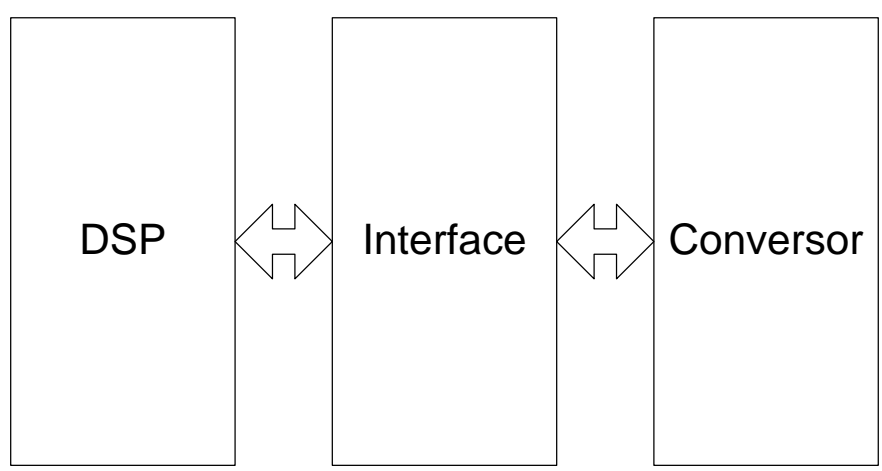

Figura 4 - Plataforma de estudos 
Na Figura 5 é apresentado o esquema do conversor DC-DC topologia Buck síncrona empregado. Vin é a tensão DC de entrada, $V o$ a tensão DC de saída, $L$ e $C$ filtros de saída. A chave $S$ comuta entre $V i n$ e a referência (terra), e $R$ representa a carga que recebe a energia convertida. Ela é denominada síncrona pelo fato do controlador comandar uma chave de forma independente tanto para a posição Vin quando para a referência.

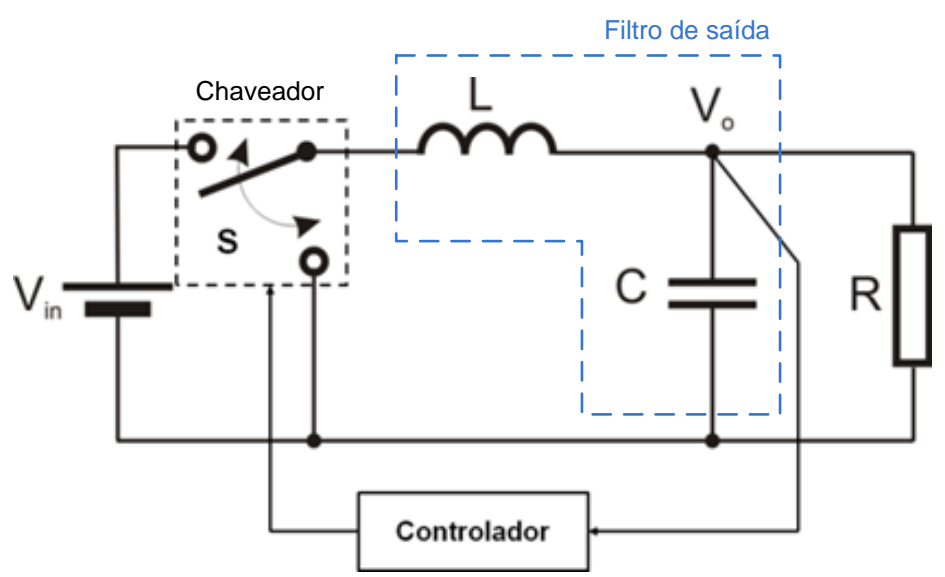

Figura 5 - Topologia Buck síncrona

O controlador mantém o nível de tensão na saída estável atuando na frequência de acionamento da chave $S$. A tensão $V o$, (1), é determinada pelo período em que a chave $S$ está ligada a Vin ou a referência. Este período, D, é denominado razão cíclica (Duty Cicle).

$$
\mathrm{V}_{\mathrm{o}}=\mathrm{D} * \mathrm{~V}_{\mathrm{in}}
$$

A chave S é implementada através de dois transistores (T1 e T2), conforme ilustra a Figura 6. Durante o chaveamento, o controlador deve evitar que ambas estejam em condução ao mesmo tempo, para evitar curtos-circuitos momentâneos na entrada que causariam um aumento na potência dissipada nos transistores e consequente queda no rendimento da conversão. Este problema é evitado inserindo-se um intervalo de tempo entre os comandos de acionamento das chaves, denominado tempo morto (dead time). Um exemplo de acionamento das chaves com tempo morto é apresentado na Figura 7. 


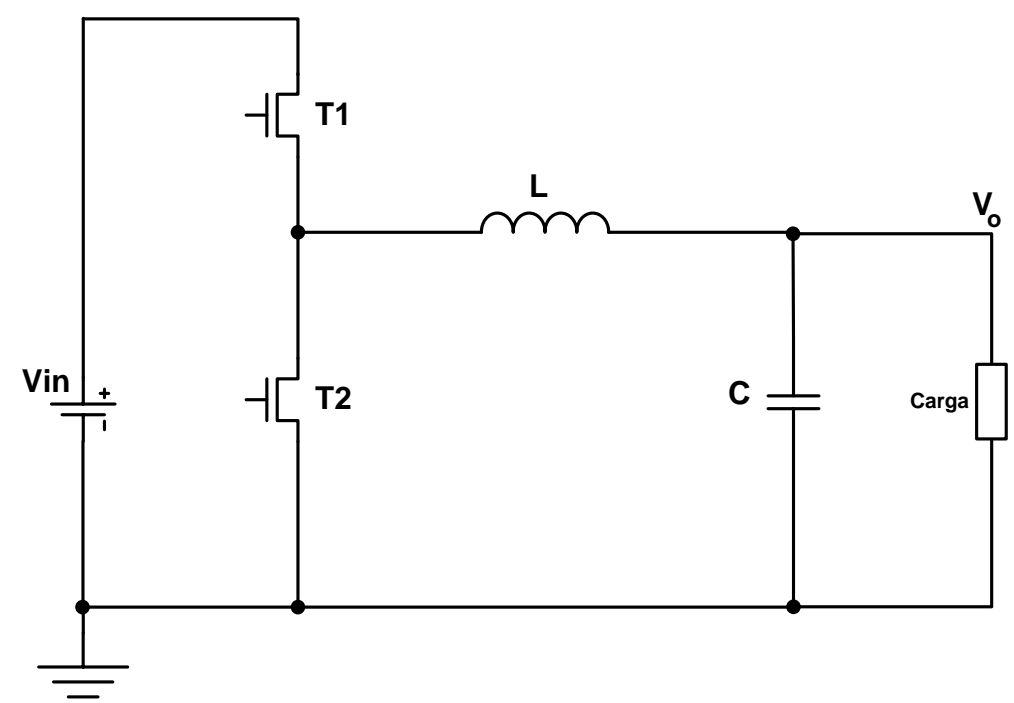

Figura 6 - Buck topologia síncrona com transistores

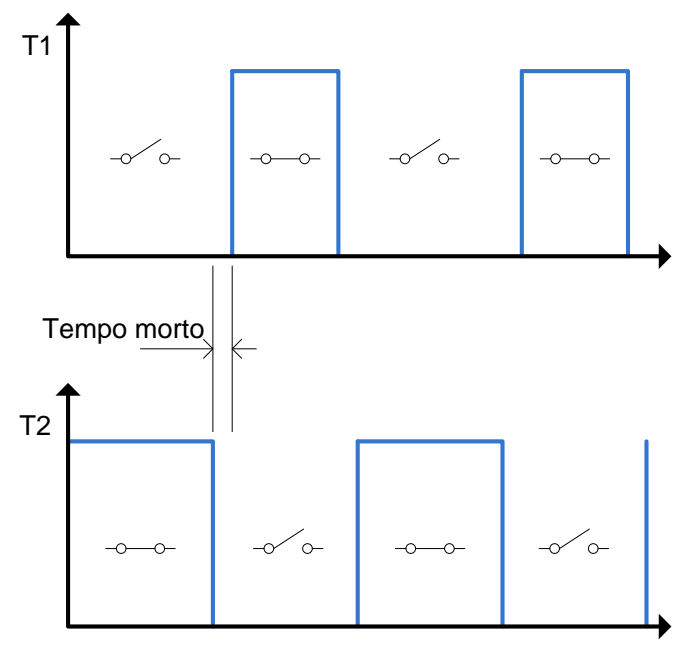

Figura 7 - Tempo morto

Um tempo morto muito curto pode não ser suficiente para evitar curtos circuitos momentâneos. Em contra partida, um tempo morto muito extenso faz com que a ação do controlador não seja eficiente. Sendo assim, o tempo morto é um parâmetro de compromisso do conversor quanto ao seu rendimento, que pode ser facilmente ajustável em implementações digitais.

O DSP selecionado para a plataforma foi o TMS320F28027 da Texas Instruments. Ele é indicado para aplicações de controle em tempo real e tem as seguintes características: frequência de operação de $60 \mathrm{MHz}$, baixo consumo, conversor A/D (Analógico Digital) de 12 bits com taxa de conversão de 6.25×106 amostras por segundo, saídas PWM (Pulse Width Modulation) e unidades de comunicação serial [6]. O desenvolvimento de sua programação pode ser integrado com o Simulink, onde é possível programar sua atitude usando controladores modelados neste programa. Outro recurso importante disponível é a biblioteca de operações matemáticas em ponto fixo chamada IQMath [7]. Com ela é possível alocar 
recursos de maneira ótima como, por exemplo, utilizar a unidade MAC (multiply-accumulate) de 32 bits disponível que realiza operações de multiplicação em dois ciclos de máquina.

A interface entre o conversor e o DSP possui circuitos especializados chamados de Gate Drivers e atenuadores. Os circuitos Gate drivers têm a função de, a partir de um estímulo causado pela saída do DSP, acionar rapidamente, e de maneira eficiente, os transistores do conversor [8].

Os atenuadores têm a função de diminuir o valor de tensão da saída para um que possa ser lido pelo conversor A/D do DSP. A Figura 8 mostra a ligação entre o conversor e o DSP através da interface.

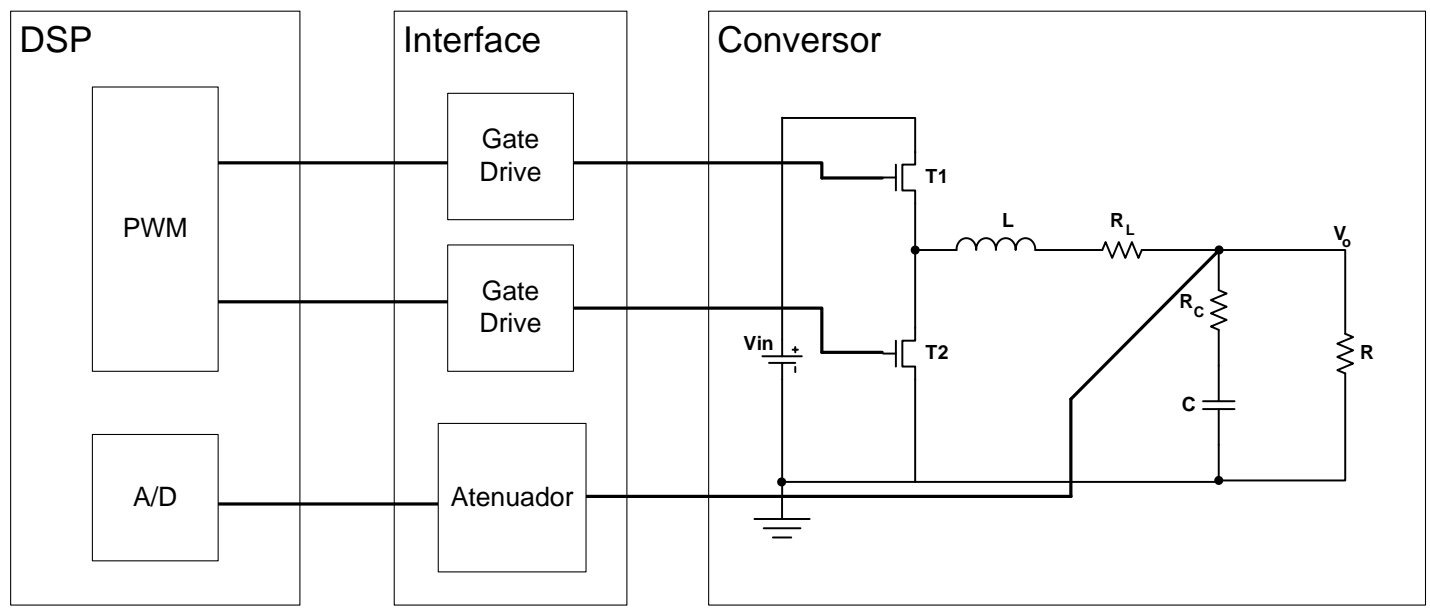

Figura 8 - Interface

\section{MODELO E CONTROLADOR}

Um modelo dinâmico do conversor foi levantado segundo a técnica de Middlebrook [4] [5]. Este modelo desconsidera as não linearidades provenientes do chaveamento e simplifica a dinâmica do sistema utilizando médias das grandezas elétricas. Na Figura 9 é apresentado o circuito equivalente para conversores topologia Buck. A função de transferência resultante é apresentada em (2). 


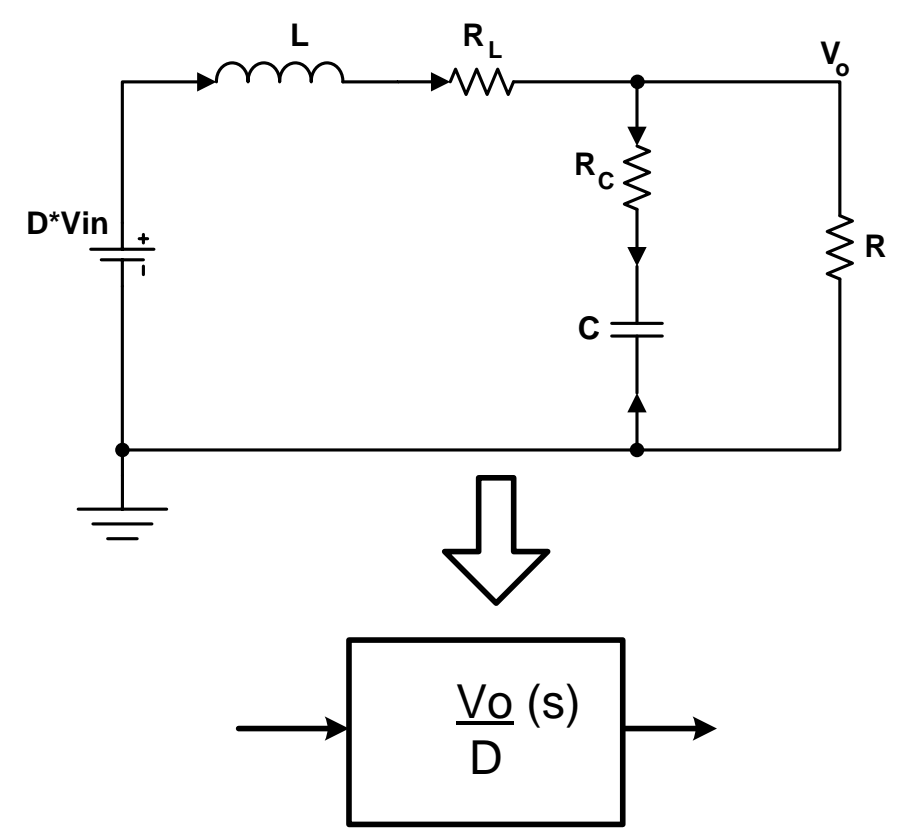

Figura 9 - Modelo de Middlebrook

$$
\frac{V_{o}(s)}{D}=\frac{7,159 * 10^{27} s+1,162 * 10^{32}}{6.596 * 10^{22} s^{2}+3.704 * 10^{26} s+4.2 * 10^{30}}
$$

No modelo, $R_{L}$ e $R_{C}$ são resistências série dos componentes do filtro de saída. Elas são consideradas no modelo por ter grande influência na resposta dinâmica do conversor.

A Figura 10 mostra o gráfico de Bode do modelo do conversor. Nele é evidenciado o efeito da ressonância do filtro de saída formado por $C$ e $L$, que é $1,27 \mathrm{kHz}$, ou $8 \mathrm{krad} / \mathrm{s}$. Uma variação de carga pode causar oscilações de tensão indesejadas nesta frequência. A função do controlador é atenuar esta ressonância e garantir robustez do conversor frente às variações de parâmetros dos componentes. 


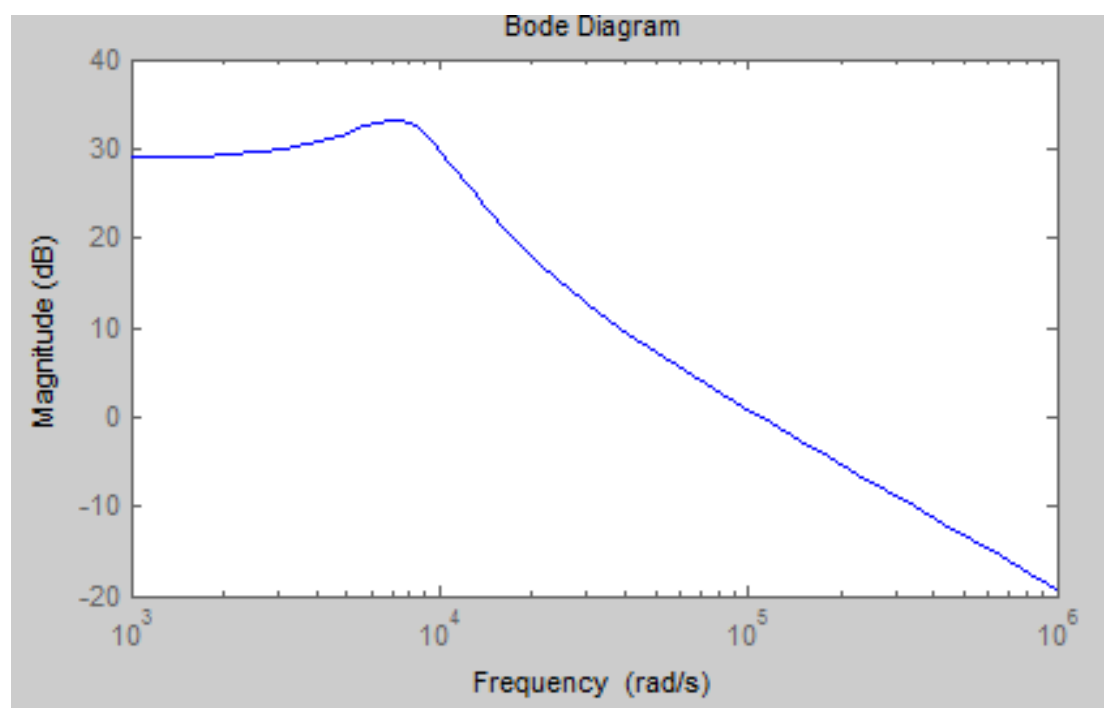

Figura 10 - Diagrame de Bode do modelo do conversor

Um controlador PID foi ajustado para que o sistema do conversor em malha aberta tenha uma largura de banda de $5 \mathrm{kHz}$, atenuando a ressonância do filtro de saída, e margem de fase de $70^{\circ}$, garantindo estabilidade e robustez frente às variações de parâmetros dos componentes. Em (3) é apresentado a equação deste controlador. A Figura 11 mostra a margem de fase resultante da malha de controle.

$$
C(s)=\frac{2,19 * 10^{6}(s+274,9)}{s\left(s+3,295 * 10^{5}\right)}
$$

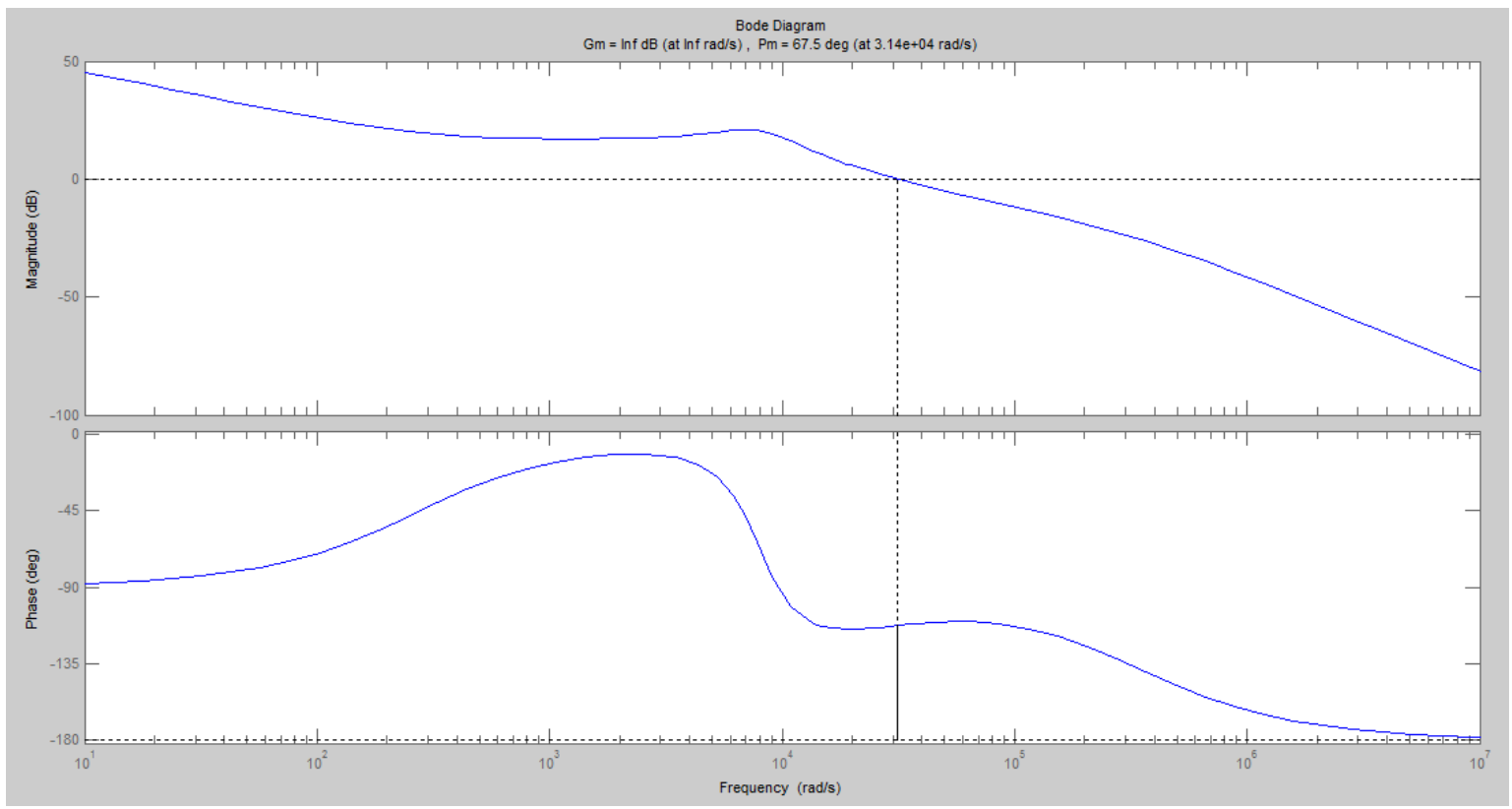

Figura 11 - Diagrame de Bode malha aberta do conversor e controlador 
O controlador projetado foi quantizado usando o método de Tusting para um período de amostragem de 100us, conforme apresentado em (4). Em (5) é apresentado a equação de diferenças do controlador.

$$
\begin{gathered}
C(z)=\frac{6,348 z^{2}+0,1721 z-6,176}{z^{2}-0,1144 z-0,8856} \\
D_{\text {out }}=\left(6,348+0,1721 z^{-1}-6,176 z^{-2}\right) D_{\text {in }}+\left(0,1144 z^{-1}+0,8856 z^{-2}\right) D_{\text {out }}
\end{gathered}
$$

A equação de diferenças foi programada no DSP através de código gerado a partir do modelo do Simulink da Figura 12. Os cálculos são realizados em números representados em pontofixo de 32 bits de resolução total com 19 bits de precisão na casa decimal. Além das operações de (5), foram acrescentadas outras duas multiplicações, uma para adaptar a tensão de saída convertida pelo A/D para um número que represente grandeza física e outra para que a ação do controlador represente razão cíclica em porcentagem.

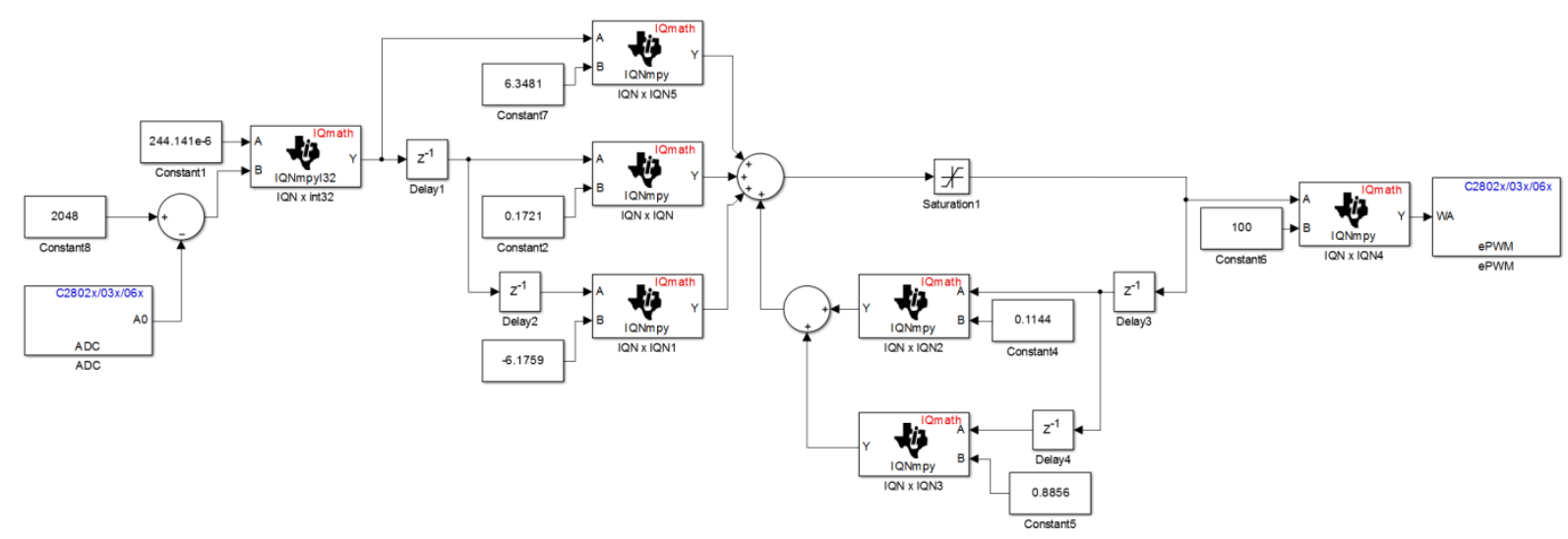

Figura 12 - Controlador no Simulink

A referência de controle empregada define a tensão de saída para 13,5V, emulando, deste modo, um conversor automotivo.

\section{TESTES}

A eficiência da conversão foi medida à temperatura ambiente, após quinze minutos de estabilização térmica, com dois valores de tempo morto programados. A fonte de entrada foi ajustada para $28 \mathrm{~V}$ e carga na saída absorvendo $405 \mathrm{~W}$, veja Tabela 1.

Tabela 1. Teste de Rendimento com diferentes valores de tempo morto

\begin{tabular}{|l|l|}
\hline Tempo morto & Rendimento \\
\hline $84 \mathrm{~ns}$ & $95,50 \%$ \\
\hline $166 \mathrm{~ns}$ & $95,14 \%$ \\
\hline
\end{tabular}


Os resultados mostram um pequeno aumento no rendimento com a diminuição do tempo morto. A influência do tempo morto no rendimento não foi maior pois parte significativa da energia é dissipada devido ao chaveamento dos transistores, à resistência dos transistores na condição ligada, e a perdas nos componentes do filtro de saída. Deve-se notar, entretanto que o tempo morto é um parâmetro de otimização, que pode compensar imperfeições dinâmicas dos transistores, como variação na quantidade de carga armazenada no gate.

Foram aplicados degraus de corrente consecutivos de 0 a 30A, com taxa de variação de $5 \mathrm{~A} / \mathrm{us}$ e período de 1 segundo, conforme Figura 13, simulando variações bruscas de carga na saída.

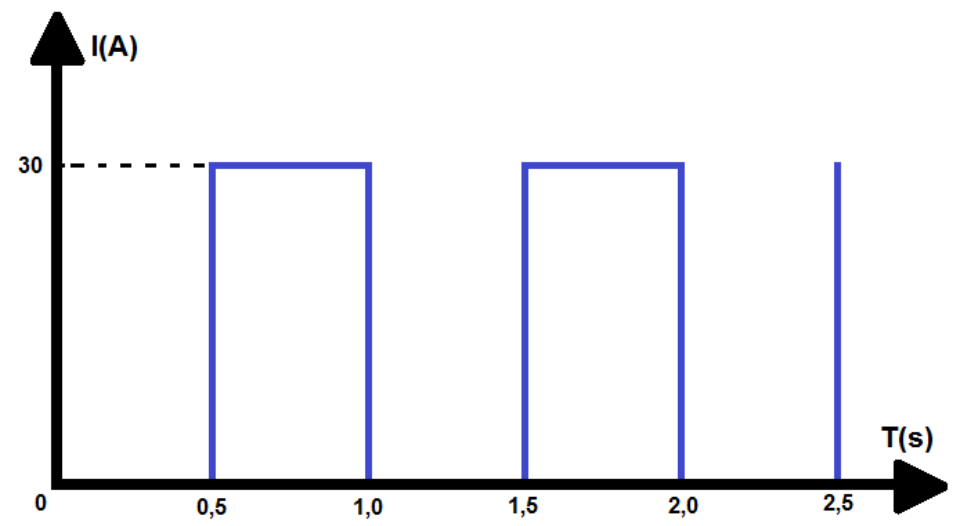

Figura 13 - Degrau de corrente

A tensão de saída do conversor foi monitorada durante a aplicação dos degraus, conforme Figura 14. A perturbação causada pelo degrau foi de 1,2V, e não foram observadas oscilações acentuadas. Deve-se notar que uma queda de $1,2 \mathrm{~V}$ é menor que o valor máximo previsto para o ambiente automotivo, conforme norma automotiva [9]. Assim, caso uma carga proveniente de módulo solicitasse 30A abruptamente ao conversor da plataforma, a tensão de saída não sofreria uma variação além da prevista pela norma.

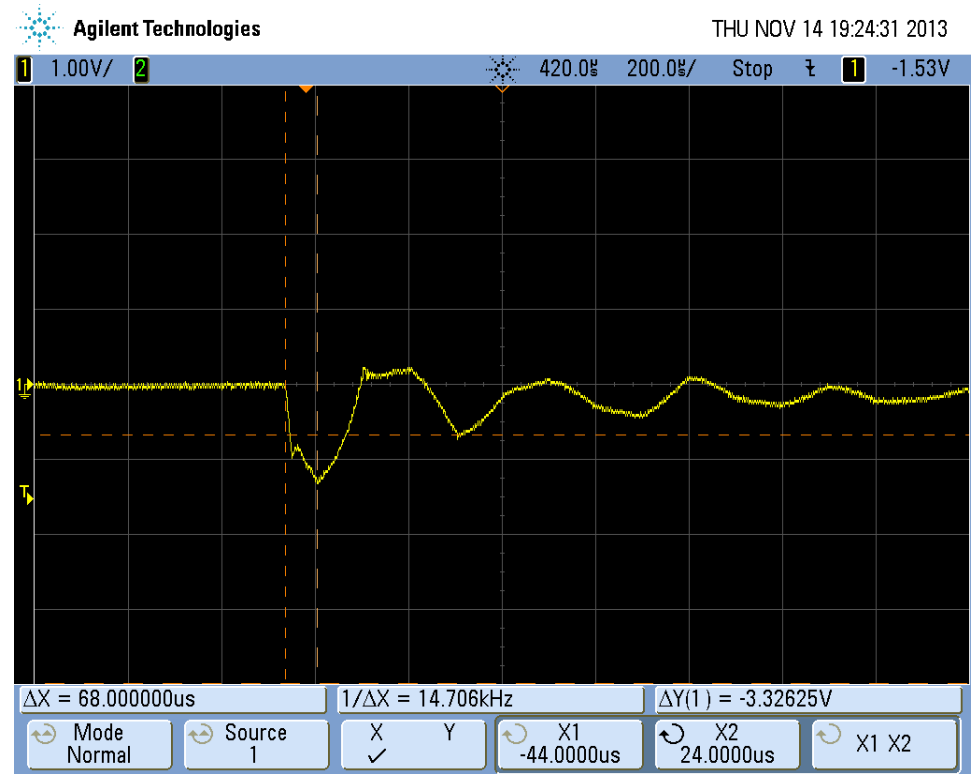

Figura 14 - Resposta da Saída do controlador digital 
Uma saída de uso geral do DSP foi configurada para monitorar o tempo de execução da rotina do controlador. Enquanto a rotina está em execução, ela é acionada em nível alto. A medição é mostrada na Figura 15. A rotina de controle apresentada, utilizando cálculos em ponto fixos e sete multiplicações em série, ocupou apenas $15 \%$ do período de execução do sistema.

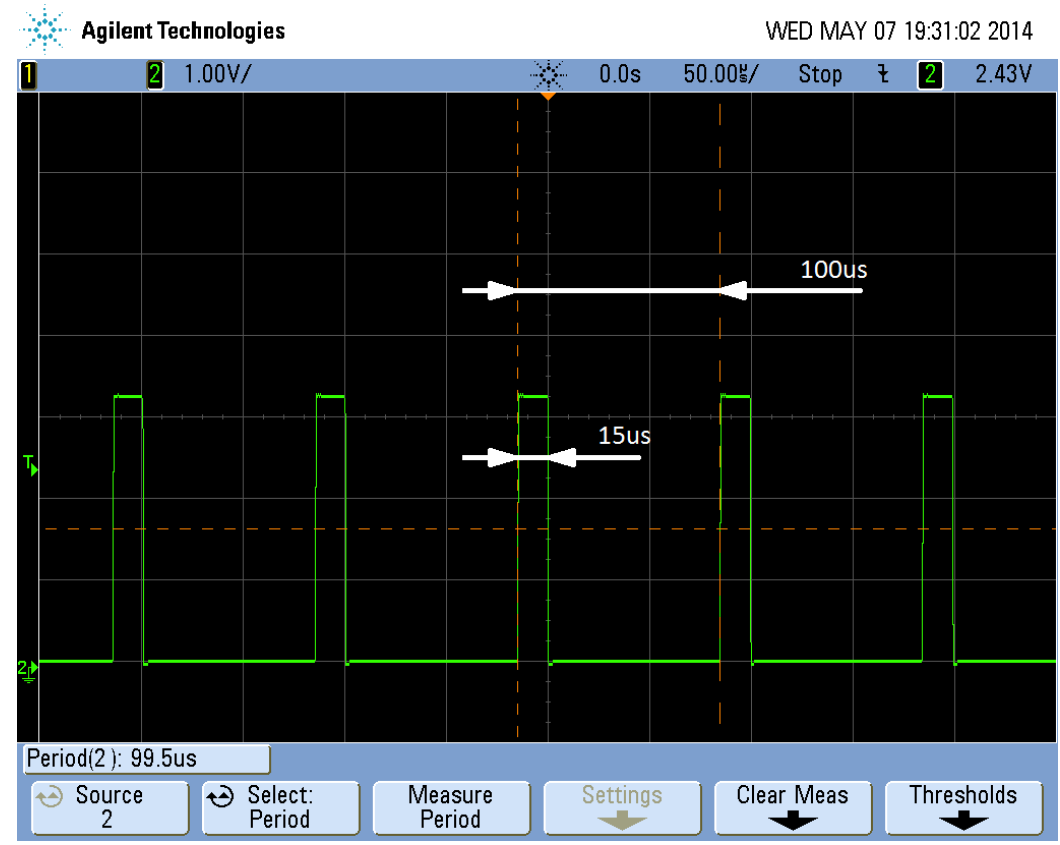

Figura 15 - Tempo de execução da rotina de controle

\section{AGRADECIMENTOS}

Os autores deste trabalho agradecem ao suporte e apoio dos profissionais Nivaldo Bissoli ( Continental Brasil Indústria Automotiva Ltda.), Nuncio Perrella e Raphael Marchi (Texas Instruments).

\section{CONCLUSÃO}

Com o uso da plataforma foi demonstrado ser possível realizar controle robusto de conversor de energia automotivo utilizando controlador digital implementado em DSP. Um controlador PID discreto foi proposto e sua robustez foi testada contra perturbações na plataforma proposta. A ação do controlador eliminou ressonância do filtro de saída e estabilizou a tensão de saída em aproximadamente 800us.

Devido a flexibilidade na programação do controle das chaves, o efeito do tempo morto na eficiência do sistema pode ser testado apenas com a alteração da programação do DSP. Assim, foi verificada a capacidade de otimização energética que a plataforma com uso de controlador digital oferece. Isto vai ao encontro com a crescente demanda por menor desperdício da energia de veículos, como é o caso dos veículos híbridos que devem aproveitar ao máximo a energia obtida da regeneração. 
Foi monitorado, também, o tempo de execução do controle proposto e verificou-se que este ocupa apenas $15 \%$ do tempo de processamento disponível. Com os $85 \%$ do tempo restante, juntamente com a disponibilidade de módulos e comunicação serial, a interação com redes de informação automotiva pode ser implementada, aumentando a integração do conversor ao sistema automotivo. 


\section{REFERÊNCIAS}

[1] MIDDLEBROOK, R. D. Power electronics: topologies, modeling and measurement. IEEE International Symposium on Circuits and Systems, Chicago IL, Abril de 1981.

[2] EHSANI, M. GAO, Y. GAY, S. E. EMADI, A. 5. Hybrid Electric Vehicles. In: Modern Electric, Hybrid Electric, and Fuel Cell Vehicles: Fundamentals, Theory and Design. Florida: CRC Press, 2005. p. $117-123$.

[3] MAKSIMOVIC, D. ; ZANE, R. ; ERICKSON, R. Impact of digital control in power electronics. IEEE Power Semiconductor Devices and ICs, p. 13 - 22, 2004.

[4] WESTER, G. W.; MIDDLEBROOK, R. D. Low-Frequency characterization of switched DC-to-DC converters. IEEE Power Processing and Electronics Specialists Conference, p. $376-385,1973$.

[5] CUK, S. Modelling, analysis, and design of switching converters. 1977. 317 f. Tese (Doutorado) - California Institute of Technology. Califórnia USA. 1977.

[6] TEXAS INSTRUMENTS INCORPORATED. Piccolo Microcontrollers TMS320F28027. Disponível em http://www.ti.com/lit/ds/symlink/tms320f28027.pdf Acesso em: 22 de julho de 2013.

[7] TEXAS INSTRUMENTS INCORPORATED. C28x IQmath Library - A Virtual Floating Point Engine - V1.5a. Texas, 2009. 74p.

[8] Gate driver. Disponível em http://en.wikipedia.org/wiki/Gate_driver. Acesso em 15 de maio de 2014.

[9] INTERNATIONAL ORGANIZATION FOR STANDARDIZATION. ISO 7637-2: Road vehicles -- Electrical disturbances from conduction and coupling -- Part 2: Electrical transient conduction along supply lines only. 2011. 